\title{
Romidepsin: evidence for its potential use to manage previously treated cutaneous $T$ cell lymphoma
}

This article was published in the following Dove Press journal:

Core Evidence

22 December 2010

Number of times this article has been viewed

\author{
Brian Poligone \\ Janet Lin \\ Catherine Chung \\ Wilmot Cancer Center, Department \\ of Dermatology, University of \\ Rochester School of Medicine, \\ Rochester, NY, USA
}

Introduction: Cutaneous T cell lymphoma (CTCL) encompasses a heterogeneous group of neoplasms of skin-homing $\mathrm{T}$ cells, which includes mycosis fungoides, the most common form, and Sézary syndrome, the leukemia equivalent of mycosis fungoides. Histone deacetylase inhibitors are currently under investigation for their therapeutic value in a variety of conditions. Through multiple mechanisms, they induce apoptosis or inhibition of tumor cell growth. Some studies have also shown histone deacetylase inhibitors to have synergistic activity with existing therapeutic agents in selected conditions. Romidepsin is a histone deacetylase inhibitor with a promising efficacy and safety profile that may represent a valuable treatment alternative for patients with treatment-resistant mycosis fungoides and Sézary syndrome.

Aims: To review emerging evidence regarding the use of romidepsin in the management of treatment-resistant CTCL.

Evidence review: There is evidence that romidepsin can induce significant and durable responses in patients with refractory CTCL. In two independent Phase II trials including a total of 167 patients with CTCL, there was an overall response rate of $34 \%$ with a partial response of $28 \%$ and complete response rate of $6 \%$. The most frequent toxicities reported from the Phase II trials were nausea, vomiting, fatigue, anorexia, and dysgeusia.

Clinical potential: Romidepsin may be an effective therapeutic option for patients with CTCL who have had treatment failure with multiple standard treatment modalities.

Keywords: cutaneous T cell lymphoma, mycosis fungoides, Sézary syndrome, romidepsin, histone deacetylase inhibitor, treatment

Core evidence clinical impact summary for romidepsin in CTCL

\begin{tabular}{|c|c|c|}
\hline Outcome measure & Evidence & Implications \\
\hline \multicolumn{3}{|l|}{ Disease-oriented evidence } \\
\hline Response rate & Substantial & $\begin{array}{l}\text { Patients with refractory CTCL have } \\
\text { partial and complete response to drug. }\end{array}$ \\
\hline Improvement in quality of life & Moderate & $\begin{array}{l}\text { Patients had a meaningful reduction in } \\
\text { pruritus. }\end{array}$ \\
\hline \multicolumn{3}{|l|}{ Patient-oriented evidence } \\
\hline Safety and tolerability & Moderate & $\begin{array}{l}\text { Grade } 3 \text { and } 4 \text { toxicities were observed } \\
\text { but infrequently led to dose limitations. }\end{array}$ \\
\hline \multicolumn{3}{|l|}{ Economic evidence } \\
\hline Health care resource utilization & Limited & $\begin{array}{l}\text { Direct cost of the drug at the approved } \\
\text { dosing level is currently higher than } \\
\text { other novel agents used in CTCL. }\end{array}$ \\
\hline Cost-effectiveness & No evidence & \\
\hline
\end{tabular}

Correspondence: Brian Poligone 601 Elmwood Avenue, Rochester, NY |4642, USA

Tel +I 585275387 I

Fax + I 585273 |346

Email brian_poligone@urmc.rochester.edu
Core Evidence 201 I:6 I-12

(C) 20I I Poligone et al, publisher and licensee Dove Medical Press Ltd. This is an Open Access article which permits unrestricted noncommercial use, provided the original work is properly cited.
Dovepress

DOI: $10.2147 /$ CE.S9084 


\section{Background}

Cutaneous T-cell lymphoma (CTCL) encompasses a heterogenous group of neoplasms of skin-homing T cells. CTCLs represent approximately $75 \%$ of all primary cutaneous lymphomas, and half of these are the most common type, mycosis fungoides. ${ }^{1}$ There are 2000 to 3000 new cases of CTCL diagnosed per year. ${ }^{2}$ Sézary syndrome, the leukemic equivalent of mycosis fungoides, is defined as having the triad of erythroderma, generalized lymphadenopathy, and the presence of neoplastic $\mathrm{T}$ cells in the skin, lymph nodes, and peripheral blood. Sézary syndrome is rare, comprising less than 5\% of all CTCLs. In general, therapies for mycosis fungoides are most effective at controlling early-stage and previously untreated disease, whereas later-stage disease, such as erythrodermic CTCL, and previously treated disease tend to be more resistant. The novel therapeutic option of histone deactylase inhibitors is being advanced in the hope of decreasing the morbidity and mortality of this disease. This review seeks to examine the basic science behind histone deacetylase inhibitors and the clinical trials investigating the use of one such histone deacetylase inhibitor, romidepsin, in patients with CTCL.

\section{Methods}

We reviewed the literature by using the PubMed database. We used the search terms "depsipeptide" and "lymphoma". The search produced 80 articles. Of these, two were reviews of CTCL therapy, nine were on the subject of histone deacetylase inhibitors, and 10 were specifically concerning romidepsin use in CTCL.

\section{Cutaneous T cell lymphoma}

CTCL is a broad term encompassing a group of cutaneous lymphomas in which $\mathrm{T}$ cells are the cell of origin causing disease. Within this type of cutaneous lymphoma, mycosis fungoides represents the majority of cases, whereas Sézary syndrome is very rare.

The incidence of mycosis fungoides is $0.41 / 100,000$ per year. ${ }^{2}$ This rate is increasing. Although it does affect all races, in the US it occurs relatively more often in black people and in males. It is typically seen in older adults, with a median age of 55-60 years at diagnosis. ${ }^{3}$ The disease is typically a chronic, slowly progressive disease that evolves through a patch stage (consisting of flat, scaly red-brown, hyperpigmented, or hypopigmented patches) and a plaque stage (in which the patches become infiltrated), and may eventually progress to the tumor stage (in which nodules appear), although the disease can have any of these lesions, as well as erythroderma, at presentation. The initial skin lesions tend to involve areas of skin not exposed to the sun, classically the buttocks and covered sites of the trunk and limbs.

In general, mycosis fungoides affects an older population and has a long evolution. Many patients do not progress beyond the patch/plaque stage. Independent markers of a poor prognosis include age of onset $>60$ years, cutaneous and lymph node stage of disease, elevated serum lactate dehydrogenase, folliculotropic disease, and thickness of the infiltrate in plaque-stage mycosis fungoides. ${ }^{4}$ Once tumors develop or lymph node involvement occurs, the prognosis becomes guarded and mycosis fungoides can be fatal.

Sézary syndrome accounts for less than $5 \%$ of all CTCL and occurs only in adults. It is defined as having the triad of erythroderma, generalized lymphadenopathy, and neoplastic T cells (Sézary cells) in the skin, lymph nodes, and peripheral blood. Criteria for the diagnosis have evolved over time, and currently include having a $\mathrm{T}$ cell clone in the peripheral blood and an absolute Sézary cell count of at least 1000 cells $/ \mu \mathrm{L}$ or a CD4:CD8 ratio $>10 .{ }^{5}$ The erythroderma may be associated with marked exfoliation, edema, and lichenification. It can be intensely pruritic. Other common findings include alopecia, onychodystrophy, and palmoplantar hyperkeratosis.

In general, Sézary syndrome is more resistant to current treatment modalities than mycosis fungoides. The prognosis is poor, with a five-year survival rate of $25 \%$. Most patients die of opportunistic infections due to immunosuppression. ${ }^{6}$

\section{Current therapy options}

In mycosis fungoides, there are two broad categories of treatment options. These are skin-targeted therapies and systemic therapies. In general, skin-directed treatments are first-line agents in early-stage disease, and systemic therapy is utilized in patients with more extensive or refractory skin disease or more advanced disease, often in combination with skin-directed treatments. ${ }^{7}$ Randomized controlled trials have demonstrated that in early-stage CTCL, systemic chemotherapy as a first-line agent did not lead to improved survival compared with skin-targeted therapy. ${ }^{8}$ Thus, systemic chemotherapy is not the treatment of choice in early disease.

Skin-targeted therapy includes topical corticosteroids, topical retinoids, topical chemotherapy, radiotherapy, phototherapy, excimer laser, photodynamic therapy, and total skin electron beam therapy. ${ }^{4,7}$ In patients with patch- or plaque-stage mycosis fungoides, topical corticosteroids and retinoids, topical chemotherapy of nitrogen mustard or carmustine, and phototherapy including ultraviolet 
A and B therapy tend to be very effective. Because excimer laser emits at a $308 \mathrm{~nm}$ wavelength within the ultraviolet $B$ range, this also has efficacy in early-stage mycosis fungoides. Photodynamic therapy has been successfully used in treatment-resistant Stage IA-IIB mycosis fungoides, but it has less effect in tumor stage or folliculotropic mycosis fungoides. Total skin electron beam irradiation is most effective in early-stage disease but is also useful in patients with advanced-stage mycosis fungoides. ${ }^{7}$

Within systemic therapy are several biologic response modifiers, the goal of which is to potentiate the host immune system response to neoplastic $\mathrm{T}$ cells. This group of medications includes, but is not limited to, cytokines, retinoids, immunotoxins, and vaccination therapy. ${ }^{4}$ The most commonly used biologic response modifier is interferon- $\alpha$, which has rates of complete remission of up to $17 \% .{ }^{9}$ Roughly similar in response rate is bexarotene, a novel retinoid-X-selective retinoid. ${ }^{10,11}$ Newer therapies include the use of cytotoxic fusion proteins. For example, denileukin diftitox is a fusion protein in which diphtheria toxin is linked to interleukin-2. In binding to the interleukin-2 receptor on neoplastic T cells, this results in inhibition of protein synthesis and cell death. ${ }^{12}$ Vaccination with peptides is currently under investigation.

The treatment regimens for Sézary syndrome are similar to those used for mycosis fungoides. However, given that Sézary syndrome is not limited to the skin, systemic treatment is generally required. Skin-targeted therapies may be used as adjuvant treatments. Traditional systemic therapies in Sézary syndrome include CHOP (cyclophosphamide, doxorubicin, vincristine, and prednisolone), interferon- $\alpha$ with or without PUVA (psoralen and long-wave ultraviolet radiation), stem cell transplant, and extracorporeal photopheresis. ${ }^{713}$ However, the list of systemic therapies has continually increased because no one therapy has proven superior in all patients, and the need for therapies for recalcitrant disease remains. The National Comprehensive Cancer Network has published guidelines on the use of many systemic therapies. ${ }^{14}$

\section{Unmet needs}

As described earlier, there are several different types of treatment modalities already in use for mycosis fungoides and Sézary syndrome. The choice of treatment is based mainly on the patient's stage of disease. Although those with patch and plaque lesions tend to do well, and mycosis fungoides itself has a chronic, slowly progressive course, those patients in the tumor stage or with lymph node involvement have significantly less durability of response and a higher chance of mortality secondary to their disease. Sézary syndrome has an even poorer prognosis, with only about a quarter of patients living beyond five years from diagnosis. ${ }^{15}$ Given this current situation, novel treatment modalities that will render less morbidity and mortality and longer duration of response are needed. Thus, the ongoing work with romidepsin, a histone deacetylase inhibitor, is an additional therapeutic approach for advanced mycosis fungoides and Sézary syndrome.

\section{Clinical evidence for romidepsin}

In 1993, romidepsin, a novel antitumor bicyclic depsipeptide $\left(\mathrm{C}_{24} \mathrm{H}_{36} \mathrm{~N}_{4} \mathrm{O}_{6} \mathrm{~S}_{2}\right)$, was isolated from the broth culture of a Gram-negative, rod-shaped motile bacterium with a single polar flagellum, Chromobacterium violaceum No. 968. In vitro studies showed that it had weak antibiotic properties and that it was able to revert the transformed morphology of an H-ras transformed cell to normal. ${ }^{16-18}$ Additional in vitro studies showed that depsipeptide (romidepsin) has potent antitumor activities against different human cell lines of lung adenocarcinoma, lung squamous cell carcinoma, gastric adenocarcinoma, mammary adenocarcinoma, and colon adenocarcinoma cell lines. ${ }^{18}$ Subsequent in vivo investigations showed that romidepsin significantly inhibited the growth of human lung and mammary adenocarcinoma that had been implanted and grown under the kidney capsule of immunosuppressed $\mathrm{BDF}_{1}$ mice. ${ }^{18}$ Also, depsipeptide, administered intravenously or intraperitoneally, prolonged the life of mice with different murine and human ascitic and solid tumors, including, but not limited to, leukemias, melanoma, colon carcinoma, and lung carcinoma. ${ }^{19}$

Further characterization of romidepsin revealed that it works on DNA within the cell nucleus as a histone deacetylase inhibitor. By altering the structure of DNA, it causes activation and/or repression of key genes in the cell cycle and apoptotic cycle (Figure 1). The nucleosome is the basic structural unit of chromatin. It is made up of 146 base pair DNA wrapped twice around an octamer of core histones, which consists of an $\mathrm{H} 3-\mathrm{H} 4$ tetramer and two $\mathrm{H} 2 \mathrm{~A}-\mathrm{H} 2 \mathrm{~B}$ dimers. The structural components of a histone can be broken down into a basic N-terminal tail region, a histone fold, and a carboxyterminal region. All of these regions, especially the N-terminus protruding from the DNA helix, are sites for a variety of covalent modifications, including acetylation. ${ }^{20}$ The hypoacetylation of histones results in a condensed chromatic structure, which leads to repression of gene transcription, whereas acetylated histones result in a more open chromatic structure, which leads to activation of gene transcription. ${ }^{17,21,22}$ 


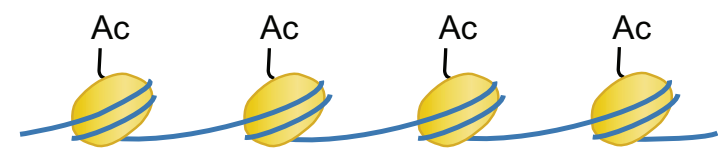

Relaxed euchromatin

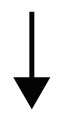

Transcription of genes involved in apoptosis and inhibition of tumor growth

Figure I HDAC mechanism of action.

Abbreviations: HDAC, histone deacetylase; HDACi, histone deacetylase inhibitors.

Histone deacetylase inhibitors have several mechanisms of action that lead to apoptosis or inhibition of tumor cell growth. Increased histone acetylation leads to the activation of transcription of a few genes that cause the inhibition of tumor growth. ${ }^{17}$ For example, p2 $1^{\mathrm{WAF} 1}$ and p2 $7^{\mathrm{KIP} 1}$ (cell cycle kinase inhibitors) are some of the most common genes induced by histone deacetylase inhibitors. ${ }^{16,23}$ Histone acetylation can lead to a conformational change that recruits repressor proteins rather than a transcriptional activator. ${ }^{17}$ A number of genes, including cyclin D1, are repressed. Activation and repression of gene expression is likely due to both direct and indirect effects. For example, the activation of a transcriptional repressor would lead to gene repression. ${ }^{17}$ Additionally, nonhistone proteins (such as p53, Rb, or Hsp90) become acetylated. ${ }^{16}$

Through a combination of the above mechanisms, the end result is that histone deacetylase inhibitors induce the accumulation of cells with a 4n DNA content, leading to apoptosis; cause upregulation of proapoptotic Fas and FasL gene transcription; alter the cell cycle, resulting in loss of

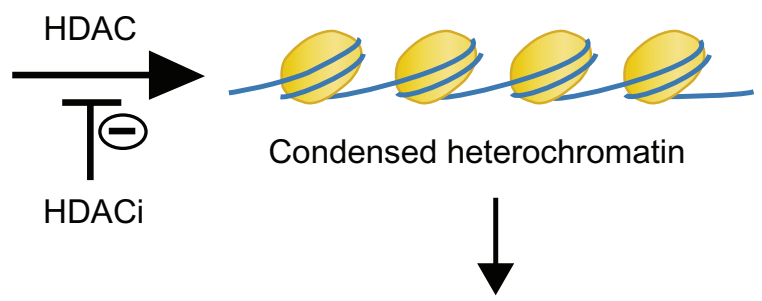

Transcription blocked tumor cells in $\mathrm{G}_{1}$ and $\mathrm{S}$ phase; ${ }^{16,23}$ activate differentiation programs; block angiogenesis; stimulate the immune system in vivo, ${ }^{23}$ and cause mitotic arrest through the formation of aberrant mitotic spindles, most likely by interfering with chromosome attachment. ${ }^{16}$

Clinical trials have demonstrated that histone deacetylase inhibitors have selective toxicity against tumor cells and synergistic activity with existing therapeutic agents, including retinoic acids in acute promyelocytic leukemia, vitamin D analogs in prostate cancer cells, and peroxisome proliferatoractivated receptor ligands in lung adenocarcinoma. ${ }^{23}$ Also, all histone deacetylase inhibitors synergize with ionizing radiation ( $\gamma$-irradiation) to kill tumor cells in vitro and in vivo. ${ }^{16,21}$

There are several classes of histone deacetylases (see Table 1). The zinc-dependent histone deacetylases include Class I enzymes (histone deacetylases 1, 2, 3, and 8), which are located in the nucleus and essential to cell proliferation and survival; Class IIa/b enzymes (histone deacetylases $4,5,6,7,9$, and 10), which move between the cytoplasm

Table I Characteristics and classifications of different histone deacetylase enzymes

\begin{tabular}{llllll}
\hline HDAC family & Class & $\begin{array}{l}\text { HDAC } \\
\text { enzyme }\end{array}$ & Location & Substrate & $\begin{array}{l}\text { Targeted by } \\
\text { HDACi? }\end{array}$ \\
\hline Zinc-dependent & I & I,2,3,8 & Nucleus & Histone & Yes \\
& Ila/b & $4,5,6,7,9,10$ & Nucleus, & Histone and & nonhistone \\
& cytoplasm & Unknown & Yes \\
Zinc-independent & IV & II & Nucleus & Nonhistone & No \\
& III & SIRT & unknown & & \\
\hline
\end{tabular}

Abbreviations: HDAC, histone deacetylase; HDACi, histone deacetylase inhibitors. 
and the nucleus and have histone and nonhistone substrates; and a Class IV enzyme (histone deacetylase 11). The zincindependent NAD-dependent histone deacetylases consist of Class III SIRT enzymes that have nonhistone substrates and are not currently targeted by available histone deacetylase inhibitors. ${ }^{16,21,22}$

Romidepsin is a relatively unusual histone deacetylase inhibitor because it is a prodrug that becomes reduced via glutathione to an active compound upon entering cells. It is then able to interact with zinc at the active site of the histone deacetylase Class I enzymes ${ }^{22}$ and also, in a much weaker fashion, the histone deacetylase Class II enzymes. ${ }^{16}$ Increased intracellular glutathione is associated with multidrug resistance-associated protein-mediated drug transport out of tumor cells. Thus, romidepsin may be a more effective therapy in tumor cells with glutathione-mediated drug resistance. ${ }^{16}$ However, romidepsin is a substrate for the drug efflux protein $\mathrm{P}$-glycoprotein. Thus, protein P-glycoprotein upregulation could potentially be a major mechanism for acquired resistance. ${ }^{16,23}$

Currently, responses with single-agent histone deacetylase inhibitors have been predominantly observed in advanced hematologic malignancies, including non-Hodgkin's T cell lymphoma, Hodgkin's lymphoma, and myeloid malignancies, with few responses in solid tumors. ${ }^{22}$

In 2002, Sandor et al conducted a Phase I trial in patients with advanced or refractory neoplasms. ${ }^{24}$ Their goals were to define the maximum tolerated dose of romidepsin, characterize the toxicities and pharmacokinetics when the medication was given on days 1 and 5 on a 21-day dosing schedule, and seek evidence of antineoplastic activity. Thirty-seven patients with advanced or refractory neoplasms were given romidepsin via a four-hour infusion on days 1 and 5 of a 21-day cycle. Because of preclinical data in dogs suggesting cardiac toxicity, patients were monitored with continuous cardiac monitoring, serial cardiac enzymes, electrocardiography (ECG), and nuclear ventriculography. Romidepsin doses were started at $1 \mathrm{mg} / \mathrm{m}^{2}$ and escalated through a total of eight dose levels to a maximum of $24.9 \mathrm{mg} / \mathrm{m}^{2}$. Toxicities were then graded according to the National Cancer Institute Common Toxicity Criteria. A dose-limiting toxicity was defined as any Grade 4 hematologic toxicity and any Grade 3 or 4 nonhematologic toxicity, excluding alopecia. The maximum tolerated dose was defined as the dose below which at least two of six patients experienced dose-limiting toxicity. Lastly, the pharmacokinetics was determined using a liquid chromatography/tandem mass spectrometry method.
In preclinical studies, greater antitumor activity was seen with an intermittent dosing schedule rather than daily because of greater host tolerance and ability to give higher individual doses. ${ }^{24}$ Also, short infusions (0.5-4.0 minutes) and prolonged infusions ( $>24$ hours) caused the greatest toxicity. ${ }^{24}$ Thus, infusions of four hours were used in this study to allow for the highest individual doses and least toxicity. ${ }^{24}$ In preclinical studies, QT interval prolongation and ST segment abnormalities were observed in Beagle dogs treated with rapid infusions of romidepsin. At lethal doses, hemorrhages were detected in multiple organs, including the heart. ${ }^{25}$

The end results of this trial were based on 37 patients treated with a total of 88 cycles, ranging from one to eight cycles per patient. This trial concluded that the maximum tolerated dose of romidepsin was $17.8 \mathrm{mg} / \mathrm{m}^{2}$. At this dose, one patient had a dose-limiting toxicity of hypocalcemia. At a dose of $24.9 \mathrm{mg} / \mathrm{m}^{2}$, the major dose-limiting toxicities were fatigue (three patients), transient thrombocytopenia, hypophosphatemia, and anorexia (two patients each), and nausea, vomiting, and hypocalcemia (one patient each). The side effect of fatigue was not associated with anemia or other defined biochemical abnormalities. This tended to be mild at the maximum tolerated dose but severe at dosing greater than the maximum tolerated dose. The hematologic changes were rapid and transient, suggesting a mechanism other than toxicity to early myeloid precursors. In fact, the thrombocytopenia and neutropenia were maximal at days 5 and 10, similar to the lifespan of these cells in circulating blood, suggesting that romidepsin may affect mature cells. The patients had no complications due to these toxicities. Although reversible ST/T wave flattening and mild reversible dysrhythmias were seen on post-treatment ECG, no clinically significant changes were seen in the left ventricular ejection fraction. One patient did develop atrial fibrillation during an episode of severe nausea and vomiting, but it was unclear whether this was incidental or truly secondary to romidepsin. Serial measurements of cardiac output by nuclear ventriculography showed no clinically significant decreases in cardiac output before and after treatment. Nausea and vomiting were associated with drug infusion. It is possible that the ECG changes were related to the use of antiemetics, which were ondansetron, prochlorperazine, and metaclopromide. ${ }^{26}$ There was no evidence for cutaneous necrosis at the intravenous catheter site and there were no patients with alopecia or mucositis. One patient did obtain a partial response after treatment, and biologic assays confirmed the ability of the serum from patients treated with romidepsin to induce cell cycle arrest 
in vivo, as well as confirmed an increase in histone acetylation in circulating mononuclear cells.

In a Phase I trial conducted at the National Cancer Institute, romidepsin was tested as single-agent treatment in four patients with T cell lymphoma (see Table 2 ). ${ }^{27}$ The study objective was to demonstrate that the inhibition of histone deacetylase is a novel and potentially effective therapy in this population of patients. In this investigation, the patients underwent a four-hour infusion of 12.7 or $17.8 \mathrm{mg} / \mathrm{m}^{2}$ on days 1 and 5 of a 21-day cycle. The disease responses were scored by World Health Organization criteria and toxicities were scored by the National Cancer Institute Common Toxicity Criteria. The patients' treated peripheral mononuclear cells and fine needle aspirates from tumors were then used to perform histone acetylation assays.

The first and second patients were both males aged 53 and 63 years and diagnosed with Sézary syndrome. Neither had responded to previous chemotherapy (cyclophosphamide, doxorubicin, vincristine, and prednisone, or cyclophosphamide, vincristine, and prednisone). After treatment with romidepsin, both had a rapid decrease of circulating Sézary cells, as well as improvement of skin erythema and edema. There was an increase in histone acetylation of peripheral mononuclear cells. Patient 1 was removed from the study after four cycles because he developed multiple subcutaneous abscesses of methicillin-resistant Staphylococcus aureus. Patient 2 was removed from the study after five cycles due to pruritus and erythema that persisted despite therapy.

The third patient was a 78-year-old male with tumorstage CTCL. He had not responded to topical therapies or total skin electron beam therapy. After the first cycle of romidepsin was completed, a fine needle aspiration of two lesions was performed. It showed many cells with vacuolization and nuclear fragmentation, suggesting that a significant population of tumor cells was affected by treatment. After six cycles, there was clearing of almost all of the tumors. Five lesions that initially responded to treatment eventually progressed and were treated with radiation.

The fourth patient was a 53-year-old male with unspecified peripheral $\mathrm{T}$ cell lymphoma. Prior to enrolling in the study, he had progression of his disease after one cycle of etoposide, prednisone, vincristine, cyclophosphamide, and doxorubicin. After initiation of romidepsin, there was clearing of his skin nodules and plaques, as well as lymphadenopathy on computed tomography scan. After the eighth cycle, he had complete remission.

In conclusion, three patients with CTCL had a partial treatment response, and one with unspecified peripheral $\mathrm{T}$ cell lymphoma had a complete response. Sézary cells isolated from patients after treatment had an increase in histone acetylation. Thus, romidepsin showed some effectiveness as single-agent treatment in patients with refractory $\mathrm{T}$ cell lymphomas.

On the basis of the observed responses in the Phase I National Cancer Institute trial, a Phase II trial of romidepsin in patients with CTCL was performed to evaluate the efficacy of the medication. ${ }^{28}$ This trial was limited to patients with relapsed, refractory, or advanced (Stage IIb-IVb) CTCL, subtypes mycosis fungoides or Sézary syndrome, who had received no more than two prior cytotoxic regimens. There were no limits on other types of therapy. This protocol was later expanded to include patients who had had prior cytotoxic regimens.

Romidepsin was initially given as a four-hour infusion of $18 \mathrm{mg} / \mathrm{m}^{2}$ on days 1 and 5 of a 21-day cycle. This was later decreased to a more tolerable schedule of $14 \mathrm{mg} / \mathrm{m}^{2}$ on days 1,8 , and 15 of a 28-day cycle. The doses were

Table 2 Summary of patient characteristics and outcomes from a Phase I trial of four patients

\begin{tabular}{|c|c|c|c|c|c|}
\hline $\begin{array}{l}\text { Patient } \\
\text { number }\end{array}$ & Age & Diagnosis & Previous treatment & Adverse effects & Outcome \\
\hline I & 53 & $\begin{array}{l}\text { Sézary } \\
\text { syndrome }\end{array}$ & $\begin{array}{l}\text { Cyclophosphamide, } \\
\text { doxorubicin, } \\
\text { vincristine, prednisone }\end{array}$ & $\begin{array}{l}\text { Multiple subcutaneous } \\
\text { MRSA abscesses }\end{array}$ & PR \\
\hline 2 & 63 & $\begin{array}{l}\text { Sézary } \\
\text { syndrome }\end{array}$ & $\begin{array}{l}\text { Cyclophosphamide, } \\
\text { vincristine, prednisone }\end{array}$ & $\begin{array}{l}\text { Pruritus, persistent } \\
\text { erythema }\end{array}$ & PR \\
\hline 3 & 78 & $\begin{array}{l}\text { Tumor } \\
\text { stage CTCL }\end{array}$ & $\begin{array}{l}\text { Topical therapies, } \\
\text { total-skin electron } \\
\text { beam therapy }\end{array}$ & & PR \\
\hline 4 & 53 & $\begin{array}{l}\text { Peripheral } \\
\text { T cell } \\
\text { lymphoma, } \\
\text { NOS }\end{array}$ & $\begin{array}{l}\text { Etoposide, prednisone, } \\
\text { vincristine, } \\
\text { cyclophosphamide, } \\
\text { doxorubicin }\end{array}$ & & $C R$ \\
\hline
\end{tabular}

Abbreviations: MRSA, methicillin-resistant Staphylococcus aureus; PR, partial response; CTCL, cutaneous T cell lymphoma; NOS, not otherwise specified; CR, complete response. 
either held or reduced to $10.5 \mathrm{mg} / \mathrm{m}^{2}$ depending on absolute neutrophil count, platelet count, or Grade 3 or worse nonhematologic toxicity. The doses were increased to $17.5 \mathrm{mg} / \mathrm{m}^{2}$ in the absence of toxicity. Radiotherapy of nonresponding lesions was allowed for patients with evidence of overall response. These irradiated lesions were not included in the final response assessment to romidepsin. Patients were given electrolyte supplementation to achieve serum magnesium $>0.85 \mathrm{mmol} / \mathrm{L}$ and potassium $>4 \mathrm{mmol} / \mathrm{L}$ before drug administration, given that $\mathrm{T}$ wave and ST segment abnormalities and QT interval prolongation were earlier findings associated with histone deacetylase inhibitor therapy. Medications that prolong the corrected QT interval $\left(\mathrm{QT}_{\mathrm{c}}\right)$ or interfere with cytochrome (CYP)3A4 metabolism were excluded because some studies showed that romidepsin may be metabolized by CYP3A4. The response evaluation included assessment of skin or visceral involvement, lymph node disease, bone marrow involvement, and flow cytometry of blood. Complete response was defined as clearing of all known sites of disease. Partial response was defined as a response in the skin or lymph nodes. Blood samples were collected before and after several time points of medication infusion for pharmacokinetic analysis.

Among the 71 patients enrolled, there was a median of four prior treatments. Sixty-two patients $(87 \%)$ had advancedstage disease (Stage IIb $=15$, Stage III $=6$, Stage IV =41) Complete responses were seen in four patients $(6 \%)$, and a partial response was seen in 20 patients $(28 \%)$, for an overall response rate of $34 \%$ (Table 3 ). Of the patients with a complete response, one patient had mycosis fungoides and three had Sézary syndrome. Two patients remain in complete remission at 26 and 63 months. Of the 20 patients with a partial response, three are still in partial remission after 11, 13, and 82 months. Of the remaining 17 patients with a partial response, 10 developed disease progression; three withdrew; three came off the study after experiencing an adverse event of fatigue, infection, or hypotension; and

Table 3 Summary of responses from a Phase II trial

\begin{tabular}{llll}
\hline Type of response & \multicolumn{2}{l}{ Total $\mathbf{n}=\mathbf{7 1}$} & $\begin{array}{l}\text { Response duration } \\
\text { (months) }\end{array}$ \\
\cline { 2 - 3 } & Number & $\%$ & \\
\hline CR & 4 & 6 & $6-63^{*}$ \\
PR & 20 & 28 & $1-76^{*}$ \\
SD & 26 & 37 & $3-11$ \\
PD & 15 & 21 & - \\
NE & 6 & 8 & - \\
\hline
\end{tabular}

Note: *At least one patient with sustained response at time of report.

Abbreviations: $C R$, complete response; PR, partial response; SD, stable disease; $\mathrm{PD}$, progressive disease; NE, not evaluable. one patient died. Twenty-six patients had stability of disease. Among patients with either complete or partial response, median time to response was two months, and the median duration of overall response was 13.7 months. The median time to disease progression was 15.1 months for patients with either a complete or partial response, 5.9 months for patients with stable disease, and 1.9 months for patients who had disease progression as the best response or who were nonevaluable. The overall responses and response durations were similar to those seen after chemotherapy, bexarotene, or denileukin diftitox.

Toxicities included nausea and vomiting, fatigue, and transient thrombocytopenia and granulocytopenia. In addition to those mentioned above, which were all previously seen toxicities, 38 patients (54\%) developed infections, including bacterial infections of the skin and upper respiratory, pulmonary, gastrointestinal, and urinary tracts, along with bacteremia and sepsis. These complications were not found to be related to neutropenia. Based on serial troponin I values, multiple-gated acquisition scans, or echocardiograms, there was no evidence of acute or cumulative cardiac damage. There was an increase in the $\mathrm{QT}_{\mathrm{c}}$ of $14 \mathrm{msec}$, for which clinical significance is still unknown.

Three total deaths occurred during the study and three within 30 days of study removal. Of the three deaths that occurred during the study, two patients died from sepsis due to Escherichia coli and methicillin-resistant Staphylococcus aureus on days 10 and 12 after romidepsin was administered, respectively. One patient who had a partial response died after his treatment course was complicated by atrial fibrillation. He had a past medical history of hypertension and severe valvular heart disease. His atrial fibrillation was treated with warfarin and digoxin. On autopsy, he was shown to have hypertrophic cardiac disease with significant valvular pathology. It was felt that his death could not be clearly attributed to romidepsin and that he had other factors that could have predisposed him to sudden death.

The authors' conclusion was that romidepsin has singleagent clinical activity, with significant and durable responses in patients with refractory CTCL. Also, because patients with Sézary syndrome are generally more refractory to available therapies, it was encouraging that three patients with Sézary syndrome had a complete response to romidepsin, with one patient continuing in complete remission at 63 months, more than 55 months after romidepsin was discontinued.

An open-label, prospective, single-arm multicenter trial in eight countries that supported the US Food and Drug Administration application for romidepsin in CTCL 
has shown similar efficacy in skin response. ${ }^{29}$ In this trial, 96 patients with Stage IB-IVA CTCL who had failed at least one prior systemic therapy were recruited. Patients received romidepsin $14 \mathrm{mg} / \mathrm{m}^{2}$ by intravenous infusion on days 1,8 , and 15 , every 28 days.

Response to the medication was assessed by determining the total tumor burden, which included cutaneous disease and lymph node and blood involvement. Cutaneous tumor burden was measured using the severity-weighted assessment tool (SWAT) and erythroderma scores. Response Evaluation Criteria in Solid Tumors (RECIST) methodology was used to assess abnormal lymph nodes, and the presence of Sézary cells was assessed by flow cytometry. A complete response was defined as complete resolution of disease in all three body compartments, and a partial response was defined as $\geq 50 \%$ improvement in the sum of the three assessments with $\geq 30 \%$ improvement in the skin, no worsening lymph nodes or Sézary cells, and no new tumors.

The study results showed an objective response rate of $34 \%$ and a complete response rate of $6 \%$ (Table 4 ). Response was seen in all stages of the disease and in all compartments as well. In the 37 patients with involvement of the blood, 12 patients $(32 \%)$ had a response to romidepsin treatment, including two patients with a complete response. The median time to response was two months and the median duration of response was 15 months. This is similar to the first Phase II trial and lends additional support for romidepsin as a therapeutic option for treatment-refractory CTCL. Also, $43 \%$ of 65 patients had a clinically meaningful improvement in pruritus (measured using a $100 \mathrm{~mm}$ visual analog scale), which lasted for a median duration of six months. This occurred despite exclusion of topical or systemic steroids and antihistamines in this study.

Similar side effects of gastrointestinal disturbances, fatigue, and weakness were noted (Table 5). In terms of cardiac side effects, reversible nonspecific ECG changes were

Table 4 Summary of responses from a Phase II trial with Stage IB-IVA disease

\begin{tabular}{|c|c|c|c|c|}
\hline \multirow{2}{*}{$\begin{array}{l}\text { Type of } \\
\text { response }\end{array}$} & \multicolumn{2}{|l|}{ Patients } & \multicolumn{2}{|c|}{ Total $n=96$} \\
\hline & $\begin{array}{l}\text { Early-stage } \\
\text { disease }(n=28)\end{array}$ & $\begin{array}{l}\text { Advanced-stage } \\
\text { disease }(n=68)\end{array}$ & Number & $\%$ \\
\hline CR & 1 & 5 & 6 & 6 \\
\hline PR & 6 & 21 & 27 & 28 \\
\hline SD & NR & NR & 45 & 47 \\
\hline PD & NR & NR & 10 & 10 \\
\hline
\end{tabular}

Abbreviations: $C R$, complete response; PR, partial response; SD, stable disease; $N R$, not reported; PD, progressive disease. noted in some patients. Because previous studies suggested that romidepsin may prolong the $\mathrm{QT}_{\mathrm{c}}$, this trial excluded people with known significant cardiac abnormalities and those receiving $\mathrm{QT}_{\mathrm{c}}$-prolonging drugs. In addition, for the first time, assessments were made of the QT $\mathrm{F}$ change from baseline before and after antiemetics were administered. This demonstrated that, in this group of patients, the mean contribution of antiemetics to the QT F was $1.3 \mathrm{msec}$ and that of romidepsin was $4.6 \mathrm{msec}$. No patient had functional cardiovascular changes of symptoms associated with prolongation of the $\mathrm{QT}_{\mathrm{c}}$.

Although the first clinical trial conducted by the National Cancer Institute revealed cases of neutropenia, leukopenia, and thrombocytopenia, only thrombocytopenia was observed in more than $10 \%$ of patients in the second study. Tumor lysis syndrome was also observed. In this trial, there was $\mathrm{QT}_{\mathrm{c}}$ prolongation, but none was felt to be clinically important. However, patients with known $\mathrm{QT}_{\mathrm{c}}$ prolongation were excluded, and magnesium and potassium levels were normalized before starting therapy. Romidepsin appears safe, with the most common adverse events related to treatment being gastrointestinal issues, ie, nausea, vomiting, and diarrhea.

In order to demonstrate that romidepsin is effective at inducing gene expression, different biomarkers in the blood and tumor biopsy samples of CTCL patients have been studied. In a study by Bates et al, four such biomarkers were investigated. ${ }^{25}$ These were histone $\mathrm{H} 3$ acetylation,

Table 5 Comparison of most common drug-related toxicities reported in two Phase II trials

\begin{tabular}{lll}
\hline Toxicity & \multicolumn{2}{l}{ Percentage of patients } \\
\cline { 2 - 3 } & $\begin{array}{l}\text { Piekarz et } \mathbf{~ a l}^{\mathbf{2 8}} \\
(\mathbf{n}=\mathbf{7 1})\end{array}$ & $\begin{array}{l}\text { Whittaker et } \mathbf{a l}^{\mathbf{2 9}, *} \\
(\mathbf{n}=\mathbf{9 6})\end{array}$ \\
\hline Nausea & 52 & 56 \\
Fatigue/asthenia & $4 \mathrm{I}$ & 44 \\
Vomiting & 19 & 26 \\
Anorexia & 21 & 20 \\
Diarrhea & 8 & 14 \\
Headache & 7 & 14 \\
Dysgeusia & 19 & $24 * *$ \\
Thrombocytopenia & 40 & $1 \mathrm{I}$ \\
Anemia & 37 & 10 \\
Leukopenia & 29 & - \\
Granulocytopenia & 36 & - \\
Hypoalbuminemia & 20 & $\mathrm{I}$ \\
Hyperglycemia & 18 & $\mathrm{I}$ \\
Hypocalcemia & 42 & - \\
Hypomagnesemia & 15 & - \\
\hline N & & \\
\hline
\end{tabular}

Notes: *Nonserious side effects affecting less than $10 \%$ of patients not reported in this study; $*^{*} 13$ of these patients experienced ageusia. 
$\mathrm{ABCB} 1$ gene expression (a reliable marker of $\mathrm{p} 21$ induction in peripheral blood mononuclear cells) in tumor biopsy samples, and blood fetal hemoglobin levels, which are a potential surrogate marker for drug effect on normal bone marrow.

In terms of global histone acetylation, there was an overall increase. At four hours, $73 \%$ of patients had evidence of at least a two-fold increase in global histone acetylation in circulating peripheral blood mononuclear cells, which persisted at that level or higher at 24 hours in $43 \%$ of patients. The global increase in histone acetylation at 24 hours not only was somewhat correlated with pharmacokinetic parameters but there was a trend that correlated with patient response $(P=0.06)$.

In blood and tissue samples, $56 \%$ of patients had ABCB1 levels two-fold or higher than baseline at four hours, and $37 \%$ had levels two-fold or higher than baseline at 24 hours. This can be compared with cell line models in which $\mathrm{ABCB} 1$ was induced to a much greater degree. It may be that constraints in the $\mathrm{ABCB} 1$ promoter are present in normal circulating white blood cells and prevent a greater increase. If so, circulating Sézary cells could in fact show a higher rate of gene expression changes in response to histone deacetylase inhibitors.

In terms of blood fetal hemoglobin levels, $73 \%$ of patients had a greater than two-fold increase, and $60 \%$ had a greater than four-fold increase. This occurred over a median time to peak of 99 days, which is compatible with a red blood cell half-life of 120 days and the fact that blood fetal hemoglobin expression may only be modulated in erythroid progenitors found in the bone marrow that populate the circulation. This suggests that the effect of repeated medication doses is cumulative. Future studies are needed to validate the ability of these biomarkers to predict the response of CTCL patients to romidepsin.

\section{Pharmacogenetics}

The future of medicine is headed toward pharmacogenetics, in which medications are tailored to work effectively for individuals based on their genetic variation. Part of making medications pharmacogenetically specific for people involves studying the effects of pharmacogenetic covariates on the pharmacokinetics of specific drugs in specific diseases. One such study looked at the effect of those variables on the pharmacokinetics of romidepsin in patients with $\mathrm{T}$ cell lymphoma. ${ }^{30}$

In this study, 98 patients in a Phase II trial were evaluated in terms of polymorphic variations in CYP3A4, CYP3A5,
SLC01B3, and ABCB1, all of which encode genes thought to be involved in romidepsin disposition. Blood samples were obtained before drug administration, at the end of infusion, and at several time points during infusion and after infusion was complete. Sixty-four patients had cutaneous $\mathrm{T}$ cell lymphoma and 34 patients had peripheral $\mathrm{T}$ cell lymphoma.

Previous studies have shown that romidepsin metabolism in vivo is primarily by CYP3A4 and to a lesser extent by CYP3A5. Preclinical studies in rats showed that $66 \%$ of the drug was excreted into bile. This was thought to be mediated via P-glycoprotein encoded by $\mathrm{ABCB} 1$, for which romidepsin has been identified as a substrate. Indeed, as previously mentioned, this is a potential pathway for resistance to romidepsin. Romidepsin is also a substrate of the organic anion transporter OATP1B3, which is an influx transporter encoded by SLC01B3.

Patient variability was $37 \%$. The overall estimated halflife was 3.5 hours. Individuals carrying the ABCB1 2677TT, 2677GA, or 2677AA genotypes trended toward a decreased clearance compared with people carrying only reference alleles or the ABCB1 2677GT genotype, but this was not statistically significant. Genetic variation in CYP3A4/5 and SCL01B3 had no effect on the systemic exposure. The authors concluded that moderate interindividual variability in romidepsin pharmacokinetics had no clinically relevant correlates.

\section{Tolerability and safety}

As previously mentioned, in preclinical studies, QT interval prolongation and ST segment abnormalities were observed in Beagle dogs treated with rapid infusions of the medication, and cardiac hemorrhages were detected on autopsy when lethal doses were administered. Because of these concerning cardiac findings, there was extensive serial cardiac monitoring. In a follow-up to the National Cancer Institute Phase II trial, ${ }^{31}$ the data from cardiac monitoring of 42 patients in that investigation were summarized. Cardiac dysfunction in relation to chemotherapy can be divided into two types. In Type I chemotherapy-related cardiac dysfunction, there is myocardial damage that may lead to impaired cardiac function and overt congestive heart failure. For example, this is known to occur with the use of anthracyclines or high doses of alkylating agents. In Type II chemotherapy-related cardiac dysfunction, the medication is not associated with myocyte damage, there is reversibility of any cardiac changes, and there is a lack of dependence on dose or re-exposure to the agent. This occurs, for example, with herceptin. 
In this retrospective cardiac summary, 2051 ECGs and 161 evaluations of left ventricular ejection fraction were studied. Although T wave flattening or ST segment depression was observed in greater than half of post-treatment ECGs, these were not associated with elevated cardiac troponin I or creatine phosphokinase or altered left ventricular function, as evidenced by echocardiograms obtained at the time of the patient's worst ECG abnormalities. No significant changes in left ventricular ejection fraction were observed. This was found to be true even if patients had been treated for prolonged periods of up to 50 months. Also, there was no clinically significant increase in serum troponin I even in patients who had prior anthracyclines and who at baseline had higher levels of cardiac troponin I than patients who had not been previously treated with anthracyclines.

Post-treatment ECGs had an average $\mathrm{QT}_{\mathrm{c}}$ prolongation of $14.4 \mathrm{msec}$. However, all patients received ondansetron, a serotonin inhibitor, for antiemetic therapy, which has been associated independently with $\mathrm{QT}_{\mathrm{c}}$ prolongation by a mean of $15 \mathrm{msec}$. This effect is seen with dolasetron, ondansetron, and palonosetron but not with granisetron. However, in general, the effects on ST/T waves and $\mathrm{QT}_{\mathrm{c}}$ have been seen for histone deacetylase inhibitors with different chemical structures from romidepsin, suggesting that this is a class effect due to the overall underlying mechanism of action. ${ }^{31}$ Other trials using histone deacetylase inhibitors other than romidepsin have shown the same ECG changes that may be related to dosing and schedule. ${ }^{32}$

In general, Class II histone deacetylases repress the activity of MEF2, a transcription factor that when released allows expression of a program of genes that result in cardiac hypertrophy. In contrast, Class I histone deacetylases (which romidepsin predominantly inhibits) are involved in the repression of an antihypertrophy program. The echocardiograms performed in the Phase II National Cancer Institute trial showed no evidence of significant change in cardiac muscle thickness.

In terms of fatalities in patients treated with romidepsin, there have been six deaths in over 450 patients treated, five of which occurred 16-60 hours after the medication had been given. Four of those five patients had significant risk factors for sudden death. For example, one patient had a neuroendocrine tumor, left ventricular hypertrophy, and uncontrolled hypertension. The authors suggested that, in future, it would be prudent to exclude patients at risk for sudden death in these trials.

The conclusion of the cardiac summary was that romidepsin is not associated with myocardial damage or impaired cardiac function. The potential effect of increased $\mathrm{QT}_{\mathrm{c}}$ remains something that is under continued study.
As mentioned earlier, other observed side effects were fatigue, nausea and vomiting, thrombocytopenia, and neutropenia. Fatigue was not significant at the maximum tolerated dose. Nausea and vomiting were associated with infusion of the medication. The hematologic effects were rapid, transient, and not associated with any complications. Due to the timing of these hematologic changes, it is felt that this is not an effect on early myeloid precursors but on mature cells.

\section{Cost-effectiveness}

Although there are several modalities available for the treatment of CTCL, the disease process tends to be progressive, and stability is short-lived in patients with advanced disease. There is still a need for new therapies and treatment regimens that will lead not only to remission but to consistent durable responses. If this can be accomplished, there will be a reduction in the financial burden on the health care system, families, treatment centers, and palliative care centers. To date, there are no studies that have investigated the financial impact of romidepsin on CTCL.

\section{Appropriate patient populations}

Based on the clinical trials performed, romidepsin is recommended for use in mycosis fungoides patients with Stage IIb-IVb disease who have failed recommended firstline treatments. Stage IIb disease includes the presence of skin tumors. Stage III includes patients with erythroderma and Stage IVa/b patients with blood or visceral involvement. Romidepsin is also appropriate for use in patients with Sézary syndrome, as described earlier.

\section{Dosing}

Romidepsin was found to have a maximum tolerated dose of $17.8 \mathrm{mg} / \mathrm{m}^{2}$ and has been used in intravenous dosing schedules of $10.5,14$, or $17.5 \mathrm{mg} / \mathrm{m}^{2}$ on days 1,5 , and 8 of a 28 -day cycle or 12.7 or $17.8 \mathrm{mg} / \mathrm{m}^{2}$ at days 1 and 5 of a 21-day cycle. Doses higher than $17.8 \mathrm{mg} / \mathrm{m}^{2}$ had doselimiting toxicities and were not well tolerated. Romidepsin was administered as a four-hour intravenous infusions. The current dosing schedule approved by the US Food and Drug Administration is $14 \mathrm{mg} / \mathrm{m}^{2}$ administered over a four-hour period on days 1,8 , and 15 of a 28 -day cycle.

\section{Conclusion}

CTCL comprises a broad group of neoplasms of skinhoming T cells. The most common form of CTCL is mycosis 
fungoides, and the less common form is Sézary syndrome. Although these two disease entities appear to be at opposite ends of a spectrum of severity, advanced mycosis fungoides and Sézary syndrome both need treatments that provide not only decreased morbidity and mortality but also a more durable period of response.

Romidepsin is a novel medication that utilizes histone acetylation in order to either activate or inhibit genes involved in the cell cycle and apoptosis. Its diverse mechanisms of action have been demonstrated to be tumor-selective and lead to partial and complete remission. It is generally well tolerated and has response rates comparable with those of existing treatments, and no clinically significant cardiac side effects can be definitively attributed to the medication. Whether romidepsin independently increases $\mathrm{QT}_{\mathrm{c}}$ apart from ondansetron and the clinical consequences of an increased $\mathrm{QT}_{\mathrm{c}}$, eg, torsades de pointes, is yet to be seen. Also, biomarkers will need to be further investigated in order to make use of them as predictors of disease response and prognosis. So far, studies on patients with different alleles coding for the enzymes involved in the metabolism of the drug demonstrate that there is no significant difference in clearance among a diverse population. Romidepsin, in conclusion, is a new, minimally immunosuppressive medication that can be utilized to treat patients with refractory mycosis fungoides or Sézary syndrome.

\section{Disclosure}

The authors report no conflicts of interest in this work.

\section{References}

1. Willemze R, Jaffe ES, Burg G, et al. WHO-EORTC classification for cutaneous lymphomas. Blood. 2005;105(10):3768-3785.

2. Bradford PT, Devesa SS, Anderson WF, Toro JR. Cutaneous lymphoma incidence patterns in the United States: A population-based study of 3884 cases. Blood. 2009;113(21):5064-5073.

3. Criscione VD, Weinstock MA. Incidence of cutaneous T-cell lymphoma in the United States, 1973-2002. Arch Dermatol. 2007;143(7): 854-859.

4. Whittaker SJ, Foss FM. Efficacy and tolerability of currently available therapies for the mycosis fungoides and Sezary syndrome variants of cutaneous T-cell lymphoma. Cancer Treat Rev. 2007;33(2):146-160.

5. Olsen E, Vonderheid E, Pimpinelli N, et al. Revisions to the staging and classification of mycosis fungoides and Sezary syndrome: A proposal of the International Society for Cutaneous Lymphomas (ISCL) and the cutaneous lymphoma task force of the European Organization of Research and Treatment of Cancer (EORTC). Blood. 2007;110(6):1713-1722.

6. Wieselthier JS, Koh HK. Sezary syndrome: Diagnosis, prognosis, and critical review of treatment options. J Am Acad Dermatol. 1990;22(3): 381-401.

7. Gardner JM, Evans KG, Musiek A, Rook AH, Kim EJ. Update on treatment of cutaneous T-cell lymphoma. Curr Opin Oncol. 2009;21(2): 131-137.
8. Kaye FJ, Bunn PA Jr, Steinberg SM, et al. A randomized trial comparing combination electron-beam radiation and chemotherapy with topical therapy in the initial treatment of mycosis fungoides. $N$ Engl J Med. 1989;321(26):1784-1790.

9. Olsen EA, Bunn PA. Interferon in the treatment of cutaneous T-cell lymphoma. Hematol Oncol Clin North Am. 1995;9(5):1089-1107.

10. Duvic M, Martin AG, Kim Y, et al. Phase 2 and 3 clinical trial of oral bexarotene (Targretin capsules) for the treatment of refractory or persistent early-stage cutaneous T-cell lymphoma. Arch Dermatol. 2001;137(5):581-593.

11. Olsen EA, Kim YH, Kuzel TM, et al. Phase IIb multicenter trial of vorinostat in patients with persistent, progressive, or treatment refractory cutaneous T-cell lymphoma. J Clin Oncol. 2007;25(21):3109-3115.

12. Foss F. Mycosis fungoides and the Sezary syndrome. Curr Opin Oncol. 2004;16(5):421-428.

13. Lansigan F, Choi J, Foss FM. Cutaneous T-cell lymphoma. Hematol Oncol Clin North Am. 2008;22(5):979-996.

14. Zelenetz AD, Advani RH, Byrd JC, et al. Non-Hodgkin's lymphomas. J Natl Compr Canc Netw. 2008;6(4):356-421.

15. Kim YH, Liu HL, Mraz-Gernhard S, Varghese A, Hoppe RT. Longterm outcome of 525 patients with mycosis fungoides and Sezary syndrome: Clinical prognostic factors and risk for disease progression. Arch Dermatol. 2003;139(7):857-866.

16. Konstantinopoulos PA, Vandoros GP, Papavassiliou AG. FK228 (depsipeptide): A HDAC inhibitor with pleiotropic antitumor activities. Cancer Chemother Pharmacol. 2006;58(5):711-715.

17. Richon VM, O’Brien JP. Histone deacetylase inhibitors: A new class of potential therapeutic agents for cancer treatment. Clin Cancer Res. 2002;8(3):662-664.

18. Ueda H, Nakajima H, Hori Y, et al. FR901228, a novel antitumor bicyclic depsipeptide produced by Chromobacterium violaceum No. 968. I. Taxonomy, fermentation, isolation, physico-chemical and biological properties, and antitumor activity. J Antibiot (Tokyo). 1994;47(3):301-310.

19. Shigematsu N, Ueda H, Takase S, Tanaka H, Yamamoto K, Tada T. FR901228, a novel antitumor bicyclic depsipeptide produced by Chromobacterium violaceum No. 968. II. Structure determination. J Antibiot (Tokyo). 1994;47(3):311-314.

20. Schrump DS. Cytotoxicity mediated by histone deacetylase inhibitors in cancer cells: Mechanisms and potential clinical implications. Clin Cancer Res. 2009;15(12):3947-3957.

21. Glaser KB. HDAC inhibitors: Clinical update and mechanism-based potential. Biochem Pharmacol. 2007;74(5):659-671.

22. Prince HM, Bishton MJ, Harrison SJ. Clinical studies of histone deacetylase inhibitors. Clin Cancer Res. 2009;15(12):3958-3969.

23. Peart MJ, Tainton KM, Ruefli AA, et al. Novel mechanisms of apoptosis induced by histone deacetylase inhibitors. Cancer Res. 2003;63(15): 4460-4471.

24. Sandor V, Bakke S, Robey RW, et al. Phase I trial of the histone deacetylase inhibitor, depsipeptide (FR901228, NSC 630176), in patients with refractory neoplasms. Clin Cancer Res. 2002;8(3):718-728.

25. Bates SE, Zhan Z, Steadman K, et al. Laboratory correlates for a phase II trial of romidepsin in cutaneous and peripheral T-cell lymphoma. Br J Haematol. 2010;148(2):256-267.

26. Keefe DL. The cardiotoxic potential of the 5-HT(3) receptor antagonist antiemetics: Is there cause for concern? Oncologist. 2002;7(1): 65-72.

27. Piekarz RL, Robey R, Sandor V, et al. Inhibitor of histone deacetylation, depsipeptide (FR901228), in the treatment of peripheral and cutaneous T-cell lymphoma: A case report. Blood. 2001;98(9):2865-2868.

28. Piekarz RL, Frye R, Turner M, et al. Phase II multi-institutional trial of the histone deacetylase inhibitor romidepsin as monotherapy for patients with cutaneous T-cell lymphoma. J Clin Oncol. 2009;27(32): 5410-5417.

29. Whittaker SJ, Demierre MF, Kim EJ, et al. Final results from a multicenter, international, pivotal study of romidepsin in refractory cutaneous T-cell lymphoma. J Clin Oncol. 2010;28(29):4485-4491. 
30. Woo S, Gardner ER, Chen X, et al. Population pharmacokinetics of romidepsin in patients with cutaneous T-cell lymphoma and relapsed peripheral T-cell lymphoma. Clin Cancer Res. 2009;15(4): 1496-1503.

31. Piekarz RL, Frye AR, Wright JJ, et al. Cardiac studies in patients treated with depsipeptide, FK228, in a phase II trial for T-cell lymphoma. Clin Cancer Res. 2006;12(12):3762-3773.
32. Molife R, Fong P, Scurr M, Judson I, Kaye S, de Bono J. HDAC inhibitors and cardiac safety. Clin Cancer Res. 2007;13(3):1068; author reply 1068-1069.

\section{Publish your work in this journal}

Core Evidence is an international, peer-reviewed open-access journal evaluating the evidence underlying the potential place in therapy of drugs throughout their development lifecycle from preclinical to postlaunch. The focus of each review is to evaluate the case for a new drug or class in outcome terms in specific indications and patient groups.
The manuscript management system is completely online and includes a very quick and fair peer-review system, which is all easy to use. Visit http://www.dovepress.com/testimonials.php to read real quotes from published authors. 